\title{
A Framework for Strategic Performance Measurement
}

\author{
P. Bradley, D. O'Sullivan, J. Browne \\ CIMRU, UCG, Galway, Ireland. \\ Tel: +353-91-750414 E-mail:Padraig.Bradley@ucg.ie
}

\begin{abstract}
Traditional performance measurement systems no longer provide companies with the information they required to compete effectively. This has led to the development of more contemporary performance measurement systems. A framework for measuring the impact on a company of the strategic decisions made by senior management is described in this paper. This framework is compared to another contemporary system and the impact of their integration on performance measurement is examined.
\end{abstract}

\section{Keywords}

Performance measurement, critical success factors,

\section{INTRODUCTION}

The take-up and use of advanced manufacturing technology by an industrial company is directly related to its ability to quantify the likely impact of such technology on its business. Major investments must be seen to be compatible with company business goals. The implementation of technologies and/or programmes - such as Flip Chip, Chip On Board (COB) and Multi Chip Modules (MCM) in the electronics industry and Concurrent Engineering (CE)/Lean Manufacturing (LM) in the engineering sector - has tremendous consequences in terms of people, skills and manufacturing systems design. The objective of the AMBITE project is to develop both a decision framework and tools to enable senior managers to determine the effects for their businesses in investing in such technologies.

This paper describes a performance measurement framework developed as part of the AMBITE project. This performance measurement framework allows the translation of a company's business plan, expressed in critical success factors, into specific performance measures. This is done by linking the critical success factors to both the specific business processes within the company and the competitive dimensions of performance (e.g. time, cost, quality, etc.) along which the company competes. A performance measurement system, called TOPP, which has been used to measure the performance of many companies throughout Europe is also described. The paper 
concludes by examining the potential benefits of combining the TOPP system with the AMBITE performance measurement framework.

\section{PERFORMANCE MEASUREMENT}

Performance measurement is the trigger for performance improvement and the statement 'if you don't measure it, then you can't improve it' very often holds to be true. In general, the activities of an organisation are usually measured using a wide range of performance measures and, based on the results obtained, management make specific decisions. However, the measures used by most enterprises are very wide ranging and are intended to show how well (or badly) the company is performing. The performance measurement systems in use today can be broken down into two general types, namely traditional and contemporary.

\subsection{Traditional Performance Measurement Systems}

Traditional performance measures have their origins in the fourteenth century with the development of double entry book-keeping (Zairi (1994), Johnson (1987), Maskell (1991)). Since then, traditional performance measures have been cost based and the evolution of these traditional performance measures has been closely coupled to that of management accounting. However, since the early twentieth century, these traditional (or cost based) performance measures have remained relatively unchanged despite all the advances that have taken place in manufacturing.

Most of the traditional performance measures used in the decision making process tend to be financial measures and business decisions are often taken in an attempt to maximize or reduce the impact of these financial measures. The traditional approach to performance measurement was based on cost accounting techniques which have been found to have the following limitations, namely (Zairi, 1994):

- Most performance measures are derived from cost accounting information.

- Cost accounting data is often based on out-dated and irrelevant principles.

- Performance is often tracked in isolated areas.

- Management decisions are based on cost-accounting information.

- Cost accounting information is unable to map process information.

- Performance measures were unable to take into account the customer perspective.

- Performance measures which produce bottom line financial results are too late for carrying out corrective action.

Although there have been dramatic changes in manufacturing techniques and technology over the last two decades, traditional performance measurement systems have stayed the same. As companies continue to use traditional performance measurement systems, workers and managers use these measures as a gauge of their performance, and thus, these measures are perceived as being important and reflecting what the company believes to be important. This is often not the case. 


\subsection{Contemporary Performance Measurement Systems}

As global competition has intensified, companies found that traditional performance measurement systems were unable to account for the changes occurring in the business environment and that the performance measures they were using were not supplying the business with the information it required to compete. This has forced companies to derive new (or contemporary) performance measurement systems that reflect the changes occurring in the business environment. Cost based measures are no longer the only basis for decision making within the company. These contemporary performance measures are based along other competitive dimension like time and quality. Maskell (1991) has identified a range of attributes that can be attributed to the new (or contemporary) performance measures, namely:

- They are directly related to the manufacturing strategy.

- They primarily use non financial measures.

- They vary between locations.

- They change over time as needs change.

- They are simple and easy to use.

- They provide fast feedback to operators and managers.

- They are intended to foster improvement rather than just monitor.

Maskell (1991) argues that these performance measures are not 'new' as most of these performance measures have been used by companies for a long time. He states that the newness stems from the importance that is attached to them. Previously, cost based performance measures were the basis for making all business decisions in a company but now these contemporary performance measures are used as the basis for decision making in companies.

Maskell also states that the introduction of new (or contemporary) performance measures should go hand in hand with the introduction of new manufacturing techniques and he argues that when introducing a new performance measurement system, the existing system has to be abandoned. If the new measures are produced in addition to the old measures, then they will not have their intended usefulness and impact. They either will be largely ignored because people are familiar with the previous methods, or both sets of measures will be used and the company will not gain the coherence and focus that the new measures are intended to offer (Maskell, 1991).

Dixon et al (1990) argue that irrespective of the competitive priorities companies pursue, successful measurement systems will share five characteristics, namely:

1. Be mutually supportive and consistent with the business operating goals, objectives, critical success factors and programs.

2. Convey information through as few and as simple a set of measures as possible.

3. Reveal how effectively customers needs and expectations are satisfied. Focus on measures that customers can see.

4. Provide a set of measurements for each organisational component that allows all members of the organisation to understand how their decisions and activities affect the entire business.

5. Support organisational learning and continuous improvement.

In the next section, the AMBITE performance measurement framework is described. This is a contemporary performance measurement system developed as part of the 
AMBITE project. The AMBITE framework allows the strategy of a company to be translated into a set of specific performance measures, which can then be used as a basis for decision making within that company. Another contemporary performance measurement system called TOPP is described and a case is made for the integration of the AMBITE and TOPP systems into a common system.

\section{THE AMBITE PERFORMANCE MEASUREMENT FRAMEWORK}

The AMBITE performance measurement framework was developed as part of the Advanced Manufacturing Business Implementation Tool for Europe (AMBITE) project (Browne, 1995). The objective of this project is to develop a set of tools and techniques that senior managers can use to assess the impacts of the strategic decisions made by their company. The AMBITE performance measurement framework provides a means of translating the business plan of a company, expressed in terms of critical success factors (CSFs) into a set of performance measures. These performance measures, while being directly related to the strategy of the company, are also process oriented. The objective of using the AMBITE framework is to translate the strategy of the company into a set of performance measures that can be used to gauge the performance of the company.

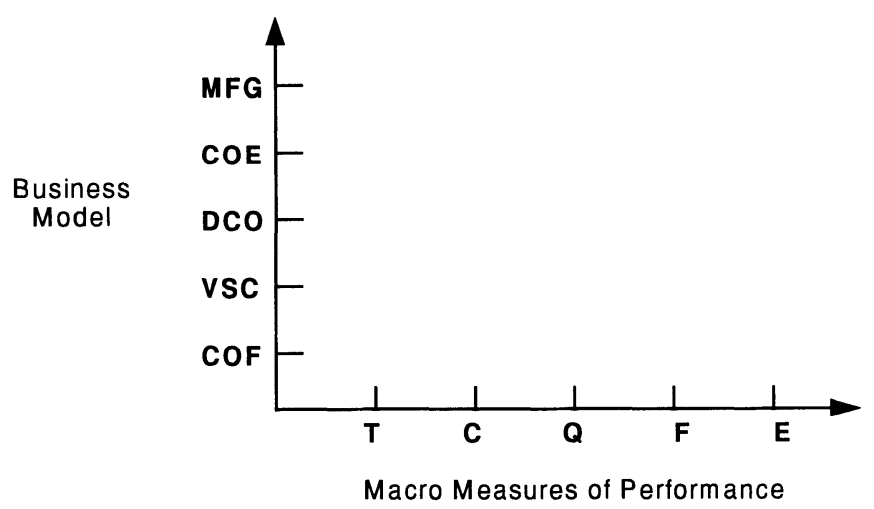

Figure 1 The AMBITE Performance Measurement Framework.

The AMBITE performance measurement framework is built around the need to develop a business model for the company and the need to identify the macro measures of performance along which the company competes. These two central axes, namely the business model and the macro measures of performance, can be represented pictorially using a two dimensional array (see Figure 1). On one dimension, the business processes identified using the business model are plotted and on the second dimension, the macro measures of performance are plotted. This mapping of business processes to macro measures of performance will be used to translate the CSFs of the company into measures of performance. 
The business model used to represent manufacturing enterprises is shown in Figure 2. Using this business model, five distinct business processes have been identified, namely (Bradley, 1994):

1. Customer Order Fulfilment Process (COF).

2. Vendor Supply Process (VSC).

3. Design Co-Ordination Process (DCO).

4. Co-Engineering Process (COE).

5. Manufacturing Process (MFG).

The customer order fulfilment process contains all the activities directly involved with the planning, control and co-ordination of customer requirements with the manufacturing process. The vendor supply process contains all of the activities directly involved in the co-ordination of supplier capabilities and the planning requirements and the delivery of these requirements to the manufacturing process. The design co-ordination process contains all of the activities directly involved in the design and development of a product and process and its release to manufacturing. The co-engineering process contains all of the activities directly involved with the coordination of supplier capabilities into the product and process design activities. The manufacturing process contains all of the activities directly involved in the physical production of the product.

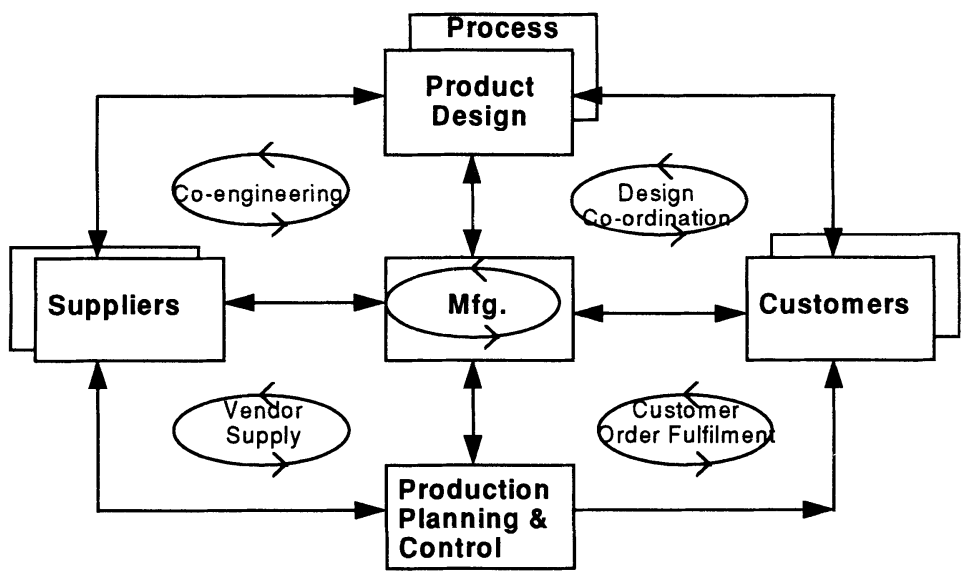

Figure 2 A Business Model for Manufacturing Enterprises (Bradley, 1994).

After the business processes have been identified using the business model, the next step involves identifying the macro measures of performance along which the manufacturing enterprise competes. Five macro measures of performance along which enterprises compete have been identified, namely: time, cost, quality, flexibility and the environment. Using the five business processes and the five macro measures of performance, a maximum of twenty-five strategic performance indicators (SPIs) can be identified. An SPI is composed of a business process and a macro measure of performance (e.g. Time in the Customer Order Fulfilment Process). When an SPI is chosen, the SPI identifies the business process that needs to be measured and identifies 
the macro measure of performance of interest for that process. Each of the twenty-five possible SPIs can be identified in the framework shown in Figure 1.

For each of the business processes identified in the business model, a high level process model is built. This high level model describes the decomposition of the business process to a number of lower levels. This process model is used to identify the process related performance measures for each business process. The process related performance measures identified will be related to the macro measures of performance chosen for that business process. For example, if time and cost are chosen as the macro measures of performance for the vendor supply process, then all of the process related performance measures used in this process will be time and cost related.

CSFs:

Shorten Order Delivery Time Increase Delivery Accuracy
PM

Framework

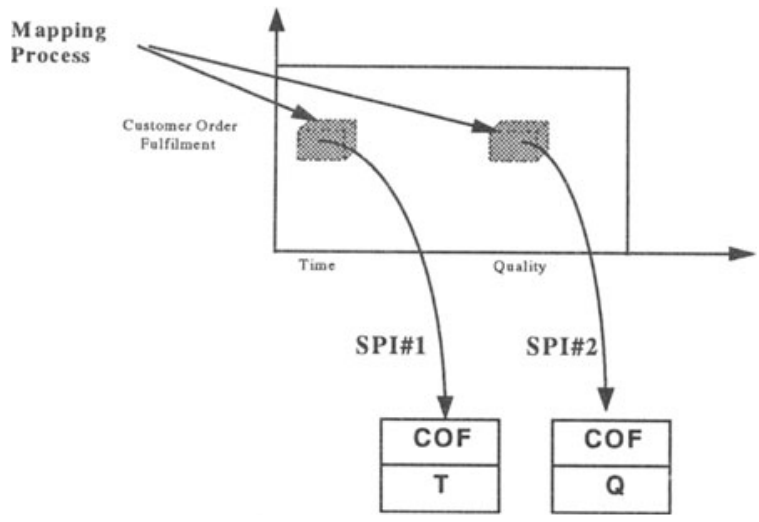

Figure 3 Using the AMBITE Performance Measurement Framework.

The process of using the AMBITE performance measurement framework to identify the SPIs that are related to two CSFs is shown in Figure 3. Based on the CSFs, the company decides that the SPIs 'Time in the Customer Order Fulfilment Process' and 'Quality in the Customer Order Fulfilment Process' are related to the CSFs 'Shorten Order Delivery Time' and 'Increase Delivery Accuracy'. From the SPIs, it is shown that the 'Customer Order Fulfilment' business process needs to measured in terms of time and quality. Then the process model of the 'Customer Order Fulfilment' process is used to identify the process-oriented time and quality performance measures. Some of the process oriented time performance measures are shown in Table 1.

The number of performance measures obtained from the process is dependant on the breadth and depth of the process model. The level of detail that is included in the process model will directly affect the number and level of performance measures that can be obtained. However, once an SPI is chosen, not all of the performance measures identified from the process model are closely related to the CSFs. Therefore, all the performance measures identified from the process model need to be sorted in order to identify the subset of performance measures that are closely related to the CSFs. These are the performance measures that should be used as a basis for making decisions within the company. 
Table 1 Some Time Performance Measures

\begin{tabular}{|c|}
\hline Time Performance Measures \\
\hline Receive Customer Order Time \\
Enter Customer Order Time \\
Plan Customer Order Time \\
Manufacture Customer Order Time \\
Collect Customer Order Time \\
Ship Customer Order Time \\
\hline
\end{tabular}

\subsection{TOPP Performance Measurement System}

TOPP is a performance measurement system for manufacturing industry that was developed by SINTEF (1992), Norway and has been used to measure the performance of manufacturing enterprises through Europe. The performance measurement system is divided into three separate parts. The first part is used to obtain an overview of the company being assessed while the second part is used to obtain a consensus on how the company operates. This consensus is obtained by surveying twenty middle managers within the company. The third part is concerned with focusing on specific areas within the company that need improvement and attempting to define the level of improvement sought in these areas. This is done by focusing on twenty different aspects of the manufacturing enterprise, namely (Sintef, 1992): marketing, material logistics, design, technological planning, production planning \& control, manufacturing/assembly, product development, top management, quality management, financial management, personnel management, maintenance, information technology, research and development, improvement processes, products, facilities, equipment, personnel and organisation.

For each of these twenty areas, a series of questions are asked, the answers to which give an indication of how the company has performed in this area and whether this area is important to the company. The answers to these questions provide an indication as to what areas of the company need improvement and the direction and level of this improvement.

\subsection{AMBITE and TOPP}

The integration of the AMBITE and TOPP performance measurement systems would produce a performance measurement system containing the strengths of both systems. This new system would use the AMBITE framework, business model and decomposition approach along with the detailed performance measurement capability provided by the TOPP questionnaire. This is due to the fact that certain parts of the TOPP system can be directly mapped to certain processes within the AMBITE system.

The TOPP system identifies twenty improvement areas, of which nine cannot be directly mapped to the AMBITE framework. Of the eleven TOPP improvement areas that are directly mapped to the AMBITE framework (see Table 2), only two of the AMBITE business processes are mapped in any detail. Two other AMBITE business processes are slightly mapped to the TOPP approach while one business process is not mapped to TOPP in any way. 
Table 2 Mapping of TOPP Improvement Areas to AMBITE Business Processes

\begin{tabular}{|c|c|c|c|}
\hline \multicolumn{2}{|c|}{ AMBITE Processes } & \multicolumn{2}{|r|}{ TOPP System } \\
\hline Process Name & Process Areas & TOPP \# & Improvement Area \\
\hline \multirow{6}{*}{$\begin{array}{c}\text { Design } \\
\text { Co-ordination }\end{array}$} & & 6000 & Marketing \\
\hline & Involve Customer & 6600 & Product Development \\
\hline & & 6200 & Design \\
\hline & Design Product & 7600 & Research \& Development \\
\hline & & 6300 & Technological Planning \\
\hline & Transfer Design & 8000 & Products \\
\hline \multirow{3}{*}{ Manufacturing } & & 6500 & Manufacturing/Assembly \\
\hline & & 7400 & Maintenance \\
\hline & & 7700 & Improvement Processes \\
\hline \multirow{3}{*}{$\begin{array}{l}\text { Customer } \\
\text { Order } \\
\text { Fulfilment }\end{array}$} & Receive Order & - -.---- & - ------ \\
\hline & Plan Production & 6400 & Production Planning \& Control \\
\hline & Ship Order & -------- & -------- \\
\hline \multirow{2}{*}{$\begin{array}{l}\text { Vendor } \\
\text { Supply } \\
\end{array}$} & Order Materials & 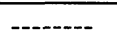 & ------- \\
\hline & Supply Materials & 6100 & Material Logistics \\
\hline Co-Engineering & & - ב-...-- & ------- \\
\hline
\end{tabular}

Using the AMBITE business model, the range of activities carried out in some of the business processes can be further sub-divided. For example, the 'Design Coordination' process can be sub-divided into three separate sets of activities, namely: involve customer, design product and transfer design. The customer involvement activities include the involvement of the customer with the marketing people in defining the requirements for a new product. The product design activities include all of the activities involved in the design of the product and process while the transfer design activities include all the activities involved in transferring the design to the manufacturing process. Each of the TOPP improvement areas mapped to the 'Design Co-ordination' process can be further mapped to each of the three activity groupings found in this process.

Table 3 Layers added to the AMBITE Framework

\begin{tabular}{cll}
\hline AMBITE & \multicolumn{2}{c}{ TOPP System } \\
\cline { 2 - 3 } Layers & TOPP \# & \multicolumn{1}{c}{ Improvement Area } \\
\hline \multirow{2}{*}{ Management } & 7000 & Top Management \\
& 7100 & Quality Management \\
& 7200 & Financial Management \\
\hline \multirow{3}{*}{ Personnel } & 7300 & Personnel Management \\
& 8300 & Personnel \\
& 8400 & Organization \\
\hline \multirow{2}{*}{ Resources } & 7500 & Information Technology \\
& 8100 & Facilities \\
\hline
\end{tabular}

The focus of the AMBITE system needs to expanded to account for the nine improvement areas identified by TOPP which cannot be mapped to the AMBITE system (see Table 3). This is done by layering the AMBITE framework to account for these improvement areas. A possible business model for this new AMBITE/TOPP 
system is shown in Figure 4. This layered business model accounts for all of the improvement areas identified by TOPP as well as the five business processes identified in the AMBITE framework.

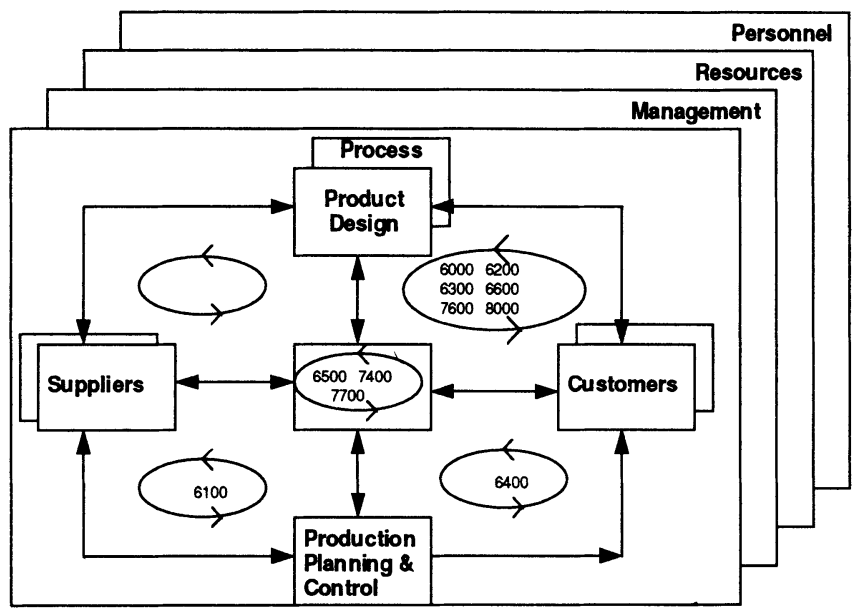

Figure 4 An Integrated AMBITE/TOPP Business Model.

\section{CONCLUSIONS}

The AMBITE performance measurement framework is described in this paper. This framework allows the strategy of a company, expressed in terms of critical success factors, to be translated into a set of performance measures. These performance measures are also related to specific high level macro measures of performance that have been defined by the company. The performance measures identified using the AMBITE framework can be used to assess the impact on the company of the strategic decisions made by senior management. Another performance measurement system, TOPP, is also described. The TOPP system uses a questionnaire format to identify a range of performance measures that can be used to assess the performance of a manufacturing business.

While both of these performance measurement systems have their merits, a new system which incorporates both the AMBITE and TOPP systems would provide an expanded focus for strategic performance measurement. The case, and an associated business model, for such a system is outlined.

\section{REFERENCES}

Bradley, P. (1994) A Generic Model of Manufacturing for AMBITE, AMBITE Report \# AMBITE/UCG/WP1/4/07///P/2.0/D, UCG.

Browne, J., Jackson, S. (1995) AMBITE 12 Monthly Progress Report, CIMRU, UCG. Dixon, J. R., Nanni, A. J., Vollmann, T. E., The New Performance Challenge,

Business One Irwin, Homewood Illinois, 1990 
Johnson, H. T., Kaplan, R. S. (1987) Relevance Lost: The Rise and Fall of Management Accounting, Harvard Business School Press, Boston MA.

Maskell, B.H. (1991) Performance Measurement for World Class Manufacturing, Productivity Press, Cambridge MA.

SINTEF (1992) TOPP: A Productivity Program for Manufacturing Industry, NTNF/NTH, Trondheim, Norway.

Zairi, M. (1994) Measuring Performance for Business Results, Chapman \& Hall, London.

\section{BIOGRAPHY}

Padraig Bradley is a Senior Research Engineer in the Computer Integrated Manufacturing Research Unit (CIMRU) at University College Galway, Ireland. He has obtained a Bachelor and Masters degree in Engineering from University College Galway. His research interests lie in the areas of manufacturing systems, business process reengineering and performance measurement.

Dr. David O'Sullivan is lecturer and research manager at University College, Galway (UCG), Ireland and a successful manufacturing consultant. David has a number of publications including a recent book entitled 'Manufacturing Systems Redesign' published by Prentice Hall. David has been honoured with the prestigious 'Outstanding Young Manufacturing Engineer of the Year' award by the Society of Manufacturing Engineers (U.S.A.) for his contributions to manufacturing industry.

Prof. Jim Browne is the Director of CIMRU, University College Galway, Ireland. He is responsible for managing research projects for CIMRU. Jim has also been engaged as a consultant by a number of Irish and European companies to work in areas such as manufacturing strategy, manufacturing systems simulation, and production planning and control. Jim has numerous publications including a number of books in the areas of production management systems, shop floor control and CAD/CAM. His interests include production planning and control, scheduling, integrated logistics, process planning, concurrent engineering and planning and simulation modelling. 